\title{
Do NGOs and Development Agencies Contribute to Sustainability of Smallholder Soybean Farmers in Northern Ghana-A Stochastic Production Frontier Approach
}

\author{
Aniah Dominic Avea ${ }^{1,2}$, Jing Zhu ${ }^{1,3}$, Xu Tian ${ }^{1,3}$, Tomas Baležentis ${ }^{4}$, Tianxiang Li ${ }^{1, *}$, \\ Michael Rickaille ${ }^{1}$ and William Funsani ${ }^{1}$ \\ 1 College of Economics and Management, Nanjing Agricultural University, Nanjing 210095, China; \\ adominicavea@gmail.com or aveadominic@yahoo.com (A.D.A.); crystalzhu@njau.edu.cn (J.Z.); \\ xutian@njau.edu.cn (X.T.); rickaille@hotmail.com (M.R.); funsaniwilliam1@yahoo.com (W.F.) \\ 2 Farmer Training Centre, Box 763, Bolgatanga 038 20, Ghana \\ 3 China Centre for Food Security, Nanjing Agricultural University, Nanjing 210095, China \\ 4 Lithuanian Institute of Agrarian Economics, V. Kudirkos g. 18-2, LT-03105 Vilnius, Lithuania; tomas@laei.lt \\ * Correspondence: garylee0428@gmail.com
}

Academic Editor: Marc A. Rosen

Received: 14 March 2016; Accepted: 6 May 2016; Published: 10 May 2016

\begin{abstract}
NGOs and development agencies have a conspicuous presence in facilitating capacity building, access to production resources and markets. Capacity building by NGOs and development agencies is expected to contribute to farm efficiency and sustainability by promoting and enhancing fertilizer use as well as increasing soil fertilities. However, the influence of these factors on technical efficiency as an important dimension of sustainability has not been further explored in Ghana. This study therefore assesses the influence of NGOs on technical efficiency among smallholder soybean farmers by applying stochastic frontier analysis. The data collected from 349 smallholder soybean producers in the three northern regions of Ghana are employed for the analysis. Results show that the mean technical efficiency of soybean production is 0.885 , indicating a growth potential of $11.5 \%$. Land area, agro-chemicals and seeds contribute to production growth while labor is over used. We find that NGO facilitation as well as group membership influences technical efficiency. Furthermore, farmers facilitated by NGOs and development agencies are 4.4 p.p. more efficient than non-facilitated farmers. Our study therefore implies that production and efficiency can be improved by providing more services to farmer group members and sustainable interventions from NGOs and social programs.
\end{abstract}

Keywords: technical efficiency; sustainability; NGOs facilitation; soybean production; stochastic production frontier; Northern Ghana

\section{Introduction}

Ghana is one of the fast-growing countries in sub-Saharan Africa and agriculture is a relatively important sector of its economy. Agriculture accounts for $22 \%$ of GDP [1] and $42 \%$ of employment in Ghana. Other sectors, such as the industrial sector, depend on the agricultural sector in terms of raw materials, especially those involved in food processing. Crop production (excluding cocoa) constitutes $61.3 \%$ of the total agricultural output [2]. Despite the enormous contribution of agriculture to the Ghanaian economy, the three northern regions which are predominantly dependent on agriculture are characterized by smallholder farming along with the poorest population. 
In recent years, due to high poverty ratings, the three northern regions have received increasing government and donor attention in the form of agricultural subsidies and social programs. Soybean is one of the crops that has been given much attention due to its potential for generating cash income to farmers and thus alleviating poverty. Despite these efforts, yield gaps and production inefficiencies still exist among smallholder farmers. According to studies by both the International Food Policy Research Institute (IFPRI) and Millennium Development Authority (MiDA) in Ghana, yields of soybean are low compared to the potential ones [3,4]. Specifically, MiDA [4] indicates a current yield of $0.8 \mathrm{t} / \mathrm{ha}$ against an achievable yield of $2 \mathrm{t} /$ ha and a potential yield of $4.5 \mathrm{t} / \mathrm{ha}$. The IFPRI GSSP 2013 report compiled by Akramov et al. [3] further reveals an average yield of $0.9 \mathrm{t} / \mathrm{ha}$ against an achievable yield of $1.6 \mathrm{t} / \mathrm{ha}$ and a potential one of $4 \mathrm{t} / \mathrm{ha}$.

Recently, the involvement of private-public partnership in soybean farming in Northern Ghana has become increasingly important. Indeed, the northern regions account for $70 \%$ of the national soybean production [5]. In 2012, private-public partnership was estimated to have resulted in an annual average production of 151,709 $\mathrm{t}$ as several NGOs, development agencies and governmental projects are involved in promoting soybean production and enhancement in its value chain. Therefore, it is important to identify the main drivers affecting farming efficiency there, as technical efficiency greatly influences output level and productivity.

The concept of technical efficiency dates back to Farrell [6] and, assuming output-orientation, can be defined as the degree to which the observed output quantity corresponds to the attainable one, given a certain amount of resources (input) exploited in the production process. The main instrument for influence of the NGOs and development agencies is their capacity building efforts via farmer-based organizations (FBOs), which help to improve the technical efficiency of farmers in a number of ways. Capacity building within the groups is fostered through the collective actions of NGOs and development agencies by providing group management training, helping to reduce transaction costs while purchasing inputs and increasing bargaining power in the market. In other instances, the FBOs provide collateral for credit for their production activities. This capacity building enhances sustainable resource utilization, especially fertilizer use, thereby improving soil fertilities. In addition, capacity building via FBOs can ensure easier access to and timely application of inputs. As indicated [7], private organizations establish FBOs to increase profits by reducing transaction costs, help in credit recovery, and helping NGOs deal effectively with smallholder farmers. Fischer and Qaim [8] also highlight the importance of farmer groups as their study indicates that farmer groups are important catalysts for innovation adoption due to efficient information flows. The FBOs also release sustainability plans to continue the facilitation works once NGO projects phase out. Considering the above-mentioned services provided to farmers by NGOs, the technical efficiency can be improved by coaching and monitoring services which enable farmers to use inputs reasonably, innovatively and timely. This is manifested by improvements in carrying out such operations as planting, fertilizer application, weeding and harvesting, where the same level of input use might render higher output quantities due to improved farming practices. Focusing on the managerial side, access to inputs and proper timing of input application is critical in agriculture. As a result, NGOs and FBOs enable farmers to achieve higher outputs with the same quantity of inputs as well as the timely use of such inputs, thereby yielding higher technical efficiency.

The involvement of NGOs in the promotion of soybean farming in Ghana is likely to positively impact sustainability on multiple dimensions. From the economic perspective, improvements in technical efficiency would ensure the viability of farming as an economic activity. From an environmental perspective, the use of fertilizers and other chemicals (which are inputs in the production model) should be balanced with economic growth to reduce their residual effects on the environment. More importantly, the efficient use of land would preserve virgin land or reduce exploitation of these areas in Northern Ghana. Focusing on the social dimension, most NGOs call for consideration of gender, child labor and environmental issues in their projects (including agricultural ones), thereby striving to increase awareness on social sustainability. The present paper, therefore, 
combines different dimensions of sustainability while looking at their linkages to technical efficiency (which, in turn, is an important component of economic sustainability).

Alternatively, some skeptics question the influence that NGOs and development organizations have on poverty alleviation and rural development. A study in Bolivia by Arellano-López and Petras [9] indicates that the success of NGOs in promoting grassroots participation for poverty alleviation is not clear and it is doubtful if NGOs are as good as they are perceived to be in championing rural development and poverty alleviation. In Ghana, some NGOs are also perceived to be used for personal gains instead of rural development or are used to project political agendas. For instance, Mohan [10] indicates, in some cases, that NGOs are used as a means of accumulating wealth by individuals through donor aids or to promote political party agendas within the communities they work in, rather than championing rural and agricultural development. However, these perceptions may be not completely valid as they ignore the influence of NGOs work on agricultural productivity improvements, especially with regards to soybean, which has received massive promotion from NGOs and development agencies in Northern Ghana.

Even though there has been literature on (i) contributions of developmental agencies and NGOs toward economic and rural development and (ii) technical efficiency in Ghanaian farms, the linkages between these two issues have not been clarified yet. This paper, indeed, seeks to fill in this gap in the literature. Etwire et al. [11] and Martey et al. [12] studied technical efficiency and productivity of soybean production in Chereponi and Saboaba districts as well as the impacts of the Agriculture Value Chain mentorship project on technical efficiency in Northern region. Djokoto [13] looked into farm technical efficiency at a national level in Ghana. Other studies $[14,15]$ discovered technical inefficiencies in the production of crops such as maize, rice, groundnuts, cocoa, and tomato in Ghana.

Focusing on other regions, Yegon et al. [16] found age, gender and education to be the key determinants of technical efficiency in Kenya, while Otitoju et al. [17] identified farm size, credit access, and extension to be the major determinants of soybean technical efficiency in Nigeria. In addition, Alwarritzi et al. [18] and Etwire et al. [11] substantiated the influence of location on technical efficiency. Social capital, as represented by farmer's education and experience, was also found to affect technical efficiency by Binam et al. [19], Abdulai and Eberlin [20], and Wilson et al. [21] in Cameroon slash and burn farming, Nicaragua, and the UK, respectively. Furthermore, Sherlund et al. [22] also found differences in production environment to have an influence on the technical efficiency of rice production in Cameroon. Lohr and Park [23] analyzed the linkages between technical efficiency and local selling decision in the US organic farming.

This study, therefore, explores the influence of NGOs and development agencies on technical efficiency of soybean production in Northern Ghana. The study also investigates determinants of technical efficiency among smallholder soybean farmers in Northern Ghana. An understanding of the determinants of technical efficiency and output of soybean, and exploring ways to increase them, are essential in identifying and developing effective and sustainable agricultural policies and projects. In addition, as indicated by Asogwa et al. [24], farming households and farming activities must be efficient for poverty eradication to be realized. Accordingly, this study will provide policy guidelines for sustaining efficiency and output improvement of soybean production through NGOs and development agencies' facilitations and projects.

The paper is structured into five sections. Section 2 explains the mechanism through which NGOs operate in Northern Ghana. The methods employed data used are presented in Section 3. Section 4 presents the key results and discussion. Conclusions and recommendations are outlined in the last section.

\section{NGOs and Soybean Promotion in Ghana}

The mechanism through which NGOs and development agencies work with farmers is based on voluntary participation and involves sensitization, registration and mobilization of targeted farmers in the target communities. On the other side, no special preference is given to any smallholder farmer in 
the community to participate in NGO activities related to soybean production. However, in one of the communities in the Upper West, women were given preferential treatment on the project since the project implemented by Tumu Denary Development Program (TUDRIDEP) and sponsored by United States Agency for International Development (USAID) sought to promote soybean production among women. Participation is usually opened to all smallholder farmers in the communities. The stage of sensitization is considered the key one in regard to decisions on participation since, at this stage, NGOs present their objectives along with means of facilitation. Furthermore, some of the NGOs develop their projects through a participatory process involving the community.

The participating farmers receive capacity development support through training and coaching on their production and marketing activities to improve their managerial skills and technical knowledge for efficient resource utilization and productivity improvement. Their production activities are then monitored by NGOs or development agencies extension officers. The NGOs and development agencies also provide support to farmers in accessing production resources such as seeds, fertilizer, agro-chemicals and machinery (sharing) services either by supplying it themselves as credit or linking them to financial institutions [25]. For instance, the Savanna Accelerated Development Authority (SADA) supplies farmers with seeds and fertilizer as credit and farmers repay during harvest while the Northern Rural Growth Program (NRGP) and NGOs such as the Association of Church-based Development Programs (ACDEP) and the International Fertilizer Development Company (IFDC) link farmers to financial institutions such as banks to access credit. The need for the NGOs to link farmers to banks to access credit is necessitated by low trust between farmers and financial institutions as well as farmer's inability to provide collateral as required by the banks for credit or loans. With regards to marketing, NGOs are either involved in scouting for markets and linking farmers with the identified markets or marketers, as in the case of the IFDC and Alliance for Green Revolution in Africa (AGRA) projects, or in establishing an aggregation company that buys produce from farmers and sells to processing companies, as in the case of the ACDEP, which, with support from the European Union (EU and ICCO), established the Savanna Farmers Marketing Company (SFMC) for buying soybean in the three Northern regions.

Furthermore, these organizations work in mostly rural areas and less developed communities, where access to improved production resources and services are rather limited. As such, NGOs and development agencies encourage farmers to form groups (FBOs) to facilitate the support provided and to improve their productive technologies. These FBOs are also used as an effective means for disseminating information among farmers on improving production practices, post-harvest management and marketing [25]. Capacity building within the groups is fostered through the collective actions of NGOs and development agencies by providing group management training, helping to reduce transaction cost in purchasing inputs, and increasing bargaining power in markets. In other instances, the FBOs secure collateral for loans and credit for their production activities as well as act as advocacy groups to champion their communities' development.

Soybean production and value chain enhancement in Northern Ghana has been championed by both international organizations (the IFDC, Cooperative for Assistance and Relief Everywhere (CARE) International, Techno-Serve Ghana, Alliance for Green Revolution in Africa (AGRA), Bill and Melinda Gates N2Africa, the IFPRI, World Vision, USAID), and domestic organizations such as the ACDEP and its networks, and government or state institutions (the Ministry of Food and Agriculture (MOFA), the Northern Rural Growth Program (NRGP), MiDA, and the Savanna Accelerated Development Authority (SADA)). Projects are sometimes implemented in partnership with several organizations. For instance, the ACDEP implemented the Farmer production and Marketing Project (FAMAR) project in all three regions in partnership with its network members such as the Farmer Training Centre (FTC), Presbyterian Agricultural Services (PAS), Evangelical Agricultural Stations (EPDRA) and the Tumu Denary Development Program (TURIDEP), which are located in different regions. Agricultural Development and Value Chain Enhancement (ADVANCE) and the ACDEP have offices in all three regions. The Alliance for Green Revolution in Africa (AGRA) and USAID operate at the national level, 
yet implement specific projects tailored for the three northern regions and in partnership with local NGOs. Specifically, local NGOs include TUDRIDEP in the upper west area, EPDRA in the northern region, FTC and PAS in both the northern and upper East region, the ACDEP, Care International and World Vision in all three northern regions. Such agencies as the IFDC and MiDA solely operate through the local NGOs. Government projects, such as NRGP and the SADA, operate within communities in the northern part collaborating extensively with local NGOs.

It is evident that farmers who are facilitated by NGOs obtain higher yields than those that are non-facilitated (Table S1). As regards input use, facilitated farmers apply higher quantities of agro-chemicals and seeds if compared to non-facilitated farmers. In addition, 59\% of facilitated farmers have access to credit compared to $15 \%$ among those non-facilitated. Similarly, $41 \%$ and $14 \%$ of facilitated and non-facilitated farmers, respectively, accessed certified/improved seeds for their production. Indeed, access to credit, the use of agrochemical and certified seeds are likely to improve technical efficiency as manifested by differences in mean yields $(1008 \mathrm{~kg} / \mathrm{ha}$ and $847 \mathrm{~kg} / \mathrm{ha}$ for facilitated and non-facilitated farms, respectively). Therefore, it can be hypothesized that NGOs influence technical efficiency through access to improved seeds, agro-chemicals and credit. Furthermore, Table S1 suggests that $97 \%$ of farmers facilitated by NGOs also belong to farmer groups. Furthermore, coaching and monitoring by NGOs enables farmers to carry out operations on their farms in a timely manner, thereby increasing productivity without additional costs. In the sequel, we look into relationships among input, output, and contextual variables within efficiency analysis framework.

\section{Methods}

\subsection{Stochastic Frontier Analysis}

The concept of technical efficiency dates back to models by Farrell [6]. The parametric approach toward efficiency measurement rests on the model for Stochastic Frontier Analysis (SFA) by Aigner et al. [26]. Battese and Coelli [27] proposed empirical models for estimating both the production function and technical efficiency simultaneously. Following [6], technical efficiency here is defined as the ratio of the observed output to the maximum attainable one given the set of inputs. In measuring efficiency indices, two approaches are usually applied, viz. SFA and Data Envelopment Analysis (DEA). These techniques mainly differ in two aspects: (i) DEA is a deterministic technique attributing the whole deviation from the production frontier to inefficiency, whereas SFA splits the error term into statistical noise and inefficiency term; (ii) contrary to SFA, DEA does not require assumption in regards to the underlying functional form of the production frontier. Given the specifics of farming in Ghana, we believe a significant part of the deviations from the frontier are likely to be due to factors outside farmers' control, e.g., weather, pests, and plant diseases. Accordingly, the levels of inefficiency reported by DEA would not provide realistic targets for improvements in productivity. Analysis of contextual variables in DEA remains a rather complicated issue and is subject to certain assumptions [28]. SFA also allows for hypothesis testing by employing appropriate tests on stochastic models. As this paper aims to identify the effects of NGO facilitation, SFA is preferred over DEA. Specifically, SFA is applied to estimate both production function and efficiency effects simultaneously.

This study uses cross sectional data, and the stochastic frontier model for estimation can be represented as follows [26]:

$$
y_{i}=f\left(x_{i}, \beta\right) \exp \left(v_{i}\right) \exp \left(-u_{i}\right)
$$

where $y_{i}$ is the output of the $i$-th farm, $x_{i}$ is vector of inputs, $\beta$ is vector of parameters to be estimated, $v_{i} \stackrel{\text { i.i.d. }}{\sim} N\left(0, \sigma_{v}^{2}\right)$ and $u_{i} \stackrel{\text { i.i.d. }}{\sim} N^{+}\left(0, \sigma_{u}^{2}\right)$ are the random error and the inefficiency term, respectively.

The technical efficiency of the $i$-th farm $\left(T E_{i}\right)$ is given by [26]:

$$
T E_{i}=\frac{y_{i}}{y_{i}^{*}}=\frac{E\left(y_{i} \mid x_{i}, u_{i}\right)}{E\left(y_{i} \mid x_{i}, u_{i}=0\right)}=\frac{f\left(x_{i}, \beta\right) \exp (v-u)}{f\left(x_{i}, \beta\right) \exp (v)}=\exp \left(-u_{i}\right)
$$


where $y_{i}=f\left(x_{i}, \beta\right) \exp \left(v_{i}-u_{i}\right)$ is the observed production with inefficiency and $y_{i}^{*}=f\left(x_{i}, \beta\right) \exp \left(v_{i}\right)$ is the frontier output quantity with no inefficiency.

The determinants of technical efficiency can be considered by simultaneously estimating production frontier and an equation for efficiency effects [27]. Therefore, technical efficiency can be explained in terms of environmental variables:

$$
\begin{aligned}
T E_{i} & =\exp \left(-u_{i}\right) \\
u_{i} & =f\left(z_{i}, \alpha\right)
\end{aligned}
$$

where $z_{i}$ is vector of environmental variables and $\alpha$ is vector of parameters to be estimated.

Therefore, the truncated normal distribution of $u_{i}$ is assumed:

$$
u_{i} \stackrel{i . i . d .}{\sim} N^{+}\left(f\left(z_{i}, \alpha\right), \sigma_{u}^{2}\right)
$$

Equations (1) and (3) can be estimated via Maximum Likelihood. The log likelihood function can be parameterized in terms of $\sigma^{2}=\sigma_{v}^{2}+\sigma_{u}^{2}$ and $\gamma=\frac{\sigma_{u}^{2}}{\sigma^{2}}$ [29]. Parameter $\gamma$ indicates the degree of variance due to technical efficiency, where $\gamma=1$ means deviations from the frontier are totally caused by technical inefficiency, whereas $\gamma=0$ implies no technical inefficiency and $0<\gamma<1$ indicates both noise and technical efficiency are responsible for deviations from the frontier.

\subsection{Empirical Model}

Translog production function is a widely used flexible form for representation of the productive technology $[15,20,27]$. Considering single output and five inputs, the translog production model is specified as

$$
\ln y_{i}=\beta_{0}+\sum_{j=1}^{5} \beta_{j} \ln x_{i j}+\sum_{j=1}^{5} \sum_{k=1}^{5} \beta_{j k} \ln x_{i j} \ln x_{i k}+\varepsilon_{i}
$$

where $j \leqslant \beta_{i k}$ and $\varepsilon_{i}=v_{i}-u_{i}$.

The dependent variable is soybean output, and the independent variables include all inputs including total labor, agro-chemicals, fertilizers, quantity of seed, and land area. The random error, $v_{i}$, follows normal distribution, whereas the technical inefficiency term, $u_{i}$, follows a truncated normal distribution $N^{+}\left(\alpha_{0}+\sum_{l=1}^{17} \alpha_{i} z_{i l}, \sigma_{u}^{2}\right)$, so that

$$
u_{i}=\alpha_{0}+\sum_{l=1}^{17} \alpha_{i} z_{i l}+\omega_{i}
$$

The dependent variable in Equation (6) is technical inefficiency $\left(u_{i}\right)$, the control variables $\left(z_{i l}\right)$ are all factors that can influence it. Apart from the conventional determinants of technical efficiency (gender, age, farming experience, education, farmer group (FBO) membership, access to credit, extension contact, household size, fertilizer use, use of improved/certified seeds and regional location), a new variable explaining the influence of NGOs on technical efficiency among smallholder soybean farmers is incorporated into the equation. This is by a dummy variable, where 1 represents a farmer facilitated by NGOs and development agencies and zero otherwise. Equations (5) and (6) were simultaneously estimated by Stata (Version 12, StataCorp LP, College Station, TX, United States).

\subsection{Study Area}

The study is conducted in the three northern regions of Ghana, which includes Upper East, Upper West and the Northern region. These three regions are considered as the Savanna Zone of Ghana and share similar climatic patterns, soil characteristics and technological availability as well as the adoption of improved production technologies. Collectively, these three northern regions make up about $41 \%$ of 
the country's total land area. Rainfall distribution in the area is uni-modal giving a single growing season of 180 to 200 days with an annual mean rainfall of $1100 \mathrm{~mm}$. The dry season starts in November and ends in March/April with maximum temperatures of about $42{ }^{\circ} \mathrm{C}$ occurring towards the end of the dry season. Soybeans, along with cotton, tomatoes and Shea butter are the major cash crops produced in the area. The major staples (crops) grown include millet, maize, rice and guinea corn as cereals. Ground nuts, cowpeas and soybeans are the major legumes while yam and sweet potato are the major tuber crops.

\subsection{Data}

Purposive sampling was used to select a representative area of seven districts or municipalities where soybean is intensively produced. In the Northern region, Saboaba, Yendi and West Manprusi districts were selected. Garu-Tempane and Bawku west Districts were selected for the Upper East. For the Upper West, Sissala West and East were the two districts selected. In each of these districts, five soybean producing communities were randomly selected and ten soybean farmers from each community. The ten farmers included both farmers facilitated by NGOs and other development organizations and those not facilitated by any development organization or NGO. A total of 349 respondents were interviewed with 155 farmers from the northern region, 99 from Upper East and 95 from the Upper West regions. Standard semi-structured and structured questionnaires were administered to these farmers on their soybean production for the 2014 production season.

The descriptive statistics and definitions for variables are given in Table 1. As regards the socio-economic characteristics of farmers, $49 \%$ are females and the average age of a farmer is 42 years with six years of soybean production experience on the average. Six years of soybean production suggest that the crop is relatively new in Northern Ghana as indicated by Rusike et al. [5]. The average level of education of farmers is three years, indicating a large portion of the farmers in Northern Ghana are not educated. The mean household size (defined as persons who eat from the same cooking pot and share common resources) is 11 persons with a minimum of three and a maximum of 70 persons.

Sixty-two percent of the farmers receive NGO facilitation, in the form of assistance on various activities such as training on production practices, financial management, marketing and group dynamics. Furthermore, most of the farmers (70\%) belong to farmer groups with $42 \%$ of all farmers accessing credit for 2014 production. The mean output produced per farmer is $801.3 \mathrm{~kg}(0.81 \mathrm{t})$, whereas the average cultivated area is $0.897 \mathrm{ha}$. The mean quantity of fertilizer applied per hectare is $32.1 \mathrm{~kg}$. This implies that most of the farmers do not apply fertilizer, and, if they do, the quantities per hectare are rather low confirming the perception that farmers in Northern Ghana follow the view that soybeans do not require fertilizer application. In addition, the mean quantity of seeds used per hectare is $28.3 \mathrm{~kg}$ which is less than the 39-40 kg recommended by Ministry of Food and Agriculture (MoFA) in Ghana. Moreover, only $23 \%$ and $30 \%$ of farmers in Northern Ghana applied fertilizer and used improved certified seeds, respectively, for soybean production. On average, three visits by extension officers per year are observed.

Note that fertilizer and seed use are represented by the two indicators each. First, input quantities are measured in respective physical quantities; second, dummies are used in the efficiency effects model to account for zero values of respective inputs (note that zero values of fertilizer inputs have been replaced by unities to ensure estimation) [30]. However, the seed dummy is only related to improved/certified seeds. Some of the variables in Table 1 were not used for estimation due to multicollinearity and/or lack of theoretical rationale. 
Table 1. Descriptive statistics of variables.

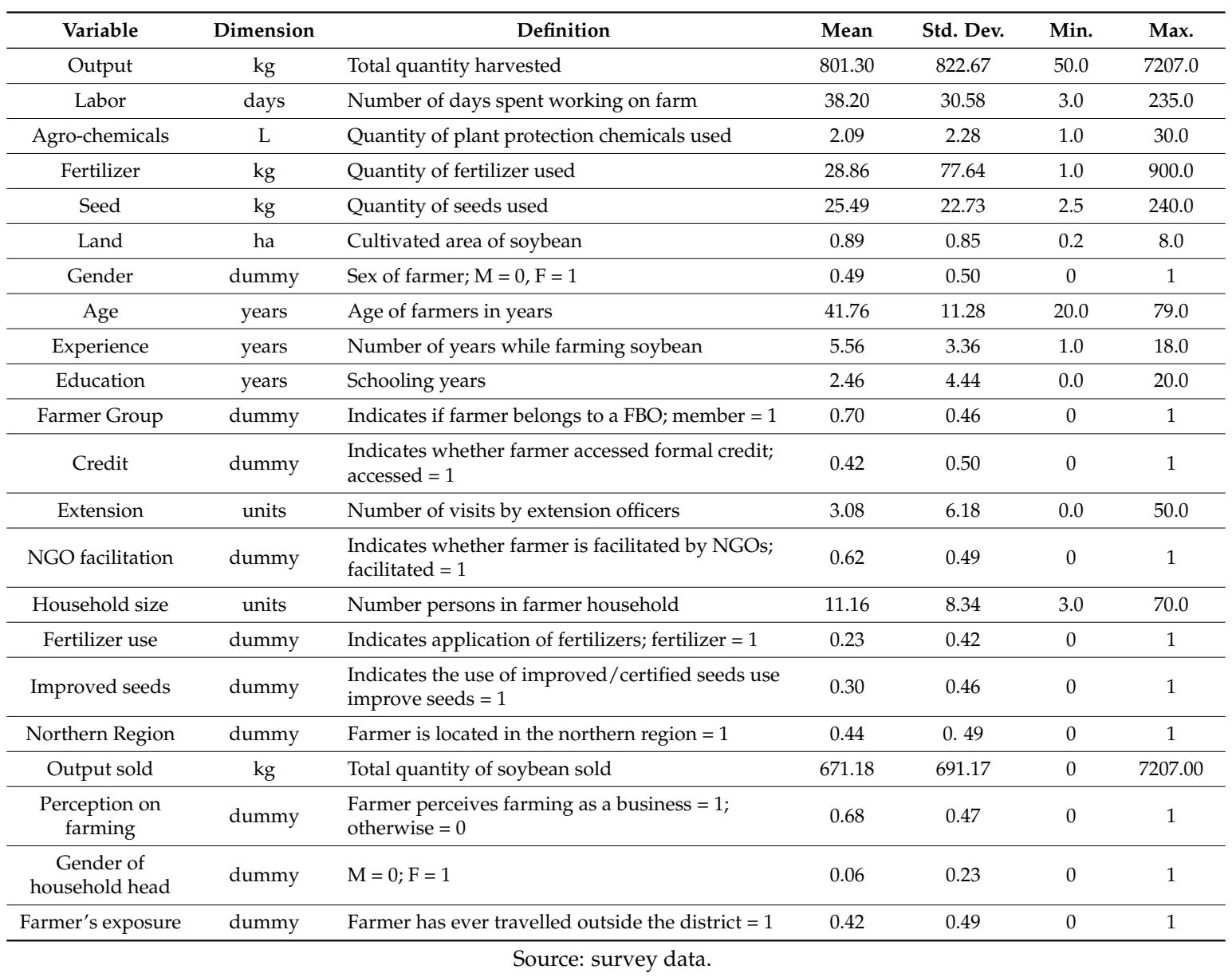

\section{Results and Discussion}

\subsection{Model Specification}

The results for model specification tests are presented in Table 2. The first null hypothesis, which indicates the translog production function can be reduced to a Cobb-Douglas function, is rejected. Therefore, translog production function is used in our analysis. The second null hypothesis indicates all variations in output are due to random or measurement error with no technical inefficiency which means that a deterministic (in the sense of error term decomposition) production function analysis is sufficient. The latter is also rejected at the $1 \%$ significance level and the stochastic production frontier approach is used for the analysis in this study. The third null hypothesis assumes no relationship between the socio-economic variables and technical inefficiencies, indicating that the socio-economic characteristics of farmers do not explain the inefficiencies in soybean production. This is also rejected at the $1 \%$ level of significance. The last hypothesis indicates that the classic inputs do not explain or influence technical inefficiency and is also rejected at a significance level of $1 \%$. Both the socio-economic variables and the classical inputs are therefore used as explanatory variables of technical inefficiency in this study. 
Table 2. Hypotheses regarding model specification.

\begin{tabular}{lcccl}
\hline \multicolumn{1}{c}{ Null Hypothesis } & DF & Chi Square & Prob $>$ Chi2 & \multicolumn{1}{c}{ Decision } \\
\hline $\mathrm{H}_{0}: \beta_{\mathrm{jk}}=0$ & 15 & 53.92 & 0.0000 & $\begin{array}{l}\text { Translog is preferred to Cobb-Douglas. } \\
\mathrm{H}_{0}: \gamma=\alpha_{0}=\ldots=\alpha_{12}=0\end{array}$ \\
& 20 & 503.82 & 0.0000 & $\begin{array}{l}\text { Presence of technical inefficiencies (SFA is } \\
\text { preferred to deterministic production function). }\end{array}$ \\
$\mathrm{H}_{0}: \alpha_{13}=\alpha_{14}=\ldots=\alpha_{17}=0$ & 16 & 34.30 & 0.0050 & $\begin{array}{l}\text { The socioeconomic variables explain } \\
\text { technical inefficiency. }\end{array}$ \\
$\mathrm{H}_{0}: \alpha_{1}=\alpha_{2}=\ldots=\alpha_{5}=0$ & 5 & 40.06 & 0.0000 & Factor inputs explain technical efficiency. \\
\hline
\end{tabular}

\subsection{Production Function of Soybean in Northern Ghana}

The results of the translog production function using stochastic frontier analysis are reported in Table 3. The results show that Soybean output in Northern Ghana is determined by factors such as cultivated land, seeds, labor and agro-chemical quantities, which are statistically significant at the level of significance of $10 \%$. The level or quantity of fertilizer, however, was not significant, yet the square quantity was significant at $1 \%$.

We also attempted to include the effect of NGOs as a frontier-shifting dummy variable in the production frontier in order to ascertain whether farm productivity is affected by the facilitation. However, the associated coefficient was not significant. One of the possible explanations could be that NGO facilitation in Ghana mainly works through improved utilization of inputs rather than expansion in the scale of operation, which would be more likely to induce frontier shifts.

Table 3. Stochastic production function.

\begin{tabular}{lcc}
\hline \multicolumn{1}{c}{ Variables } & Coefficients & $t$-Statistic \\
\hline Intercept & -2.726 & -1.181 \\
Labor & $1.793^{* * *}$ & 3.127 \\
Agro-Chemicals & $-1.666^{* *}$ & -2.277 \\
Fertilizer & -0.006 & -0.025 \\
Seed & $3.643^{* *}$ & 2.567 \\
Land & $-2.217^{*}$ & -1.718 \\
Labor Square & 0.048 & 0.573 \\
Agro-Chemicals Square & 0.036 & 0.488 \\
Fertilizer Square & $0.071^{* * *}$ & 3.837 \\
Seed Square & -0.094 & -0.415 \\
Land Square & -0.276 & -1.355 \\
Labor $\times$ Agro-Chemicals & 0.129 & 0.990 \\
Labor $\times$ Fertilizer & $-0.068^{*}$ & -1.697 \\
Labor $\times$ Seed & $-0.712^{* * *}$ & -3.463 \\
Labor $\times$ Land & 0.276 & 1.453 \\
Agro-Chemicals $\times$ Fertilizer & 0.050 & 1.530 \\
Agro-Chemicals $\times$ Seed & $0.356^{*}$ & 1.692 \\
Agro-Chemicals $\times$ Land & $-0.429^{* *}$ & -2.375 \\
Fertilizer $\times$ Seed & -0.047 & -0.893 \\
Fertilizer $\times$ Land & 0.026 & 0.512 \\
Seed $\times$ Land & 0.580 & 1.428 \\
Sigma_U & $0.204^{* * *}$ & 0.071 \\
Sigma_V & $0.42^{* * *}$ & 0.017 \\
\hline
\end{tabular}

Notes: (i) $p$-values are denoted as follows: ${ }^{*} p<0.1{ }^{* *} p<0.05$; ${ }^{* * *} p<0.01$; (ii) the production frontier is estimated simultaneously with efficiency effects. 
Without mean scaling, the results in Table 3 are first order coefficients of the flexible translog production frontier and cannot be interpreted directly. Therefore, we calculate the partial input elasticities using sample means and following Abdulai and Eberlin [20], Xu et al. [31]:

$$
e_{j}=\frac{\partial \ln y_{i}}{\partial \ln x_{i j}}=\beta_{j}+\sum_{k=1}^{4} \beta_{j k} \ln x_{k}+2 \beta_{j j} \ln x_{j}
$$

Table 4 reports the resulting estimates of input and scale elasticities. Note that labor is the only input featuring negative elasticity. The remaining inputs all show positive elasticities.

The higher rates of returns to land and seeds suggest that the increase in soybean production is mainly a result of expansion of the land area. This is not surprising as land is not a major limitation to production in Northern Ghana. This result corresponds to that of Abdulai et al. [32] who found land, seeds, and agro-chemicals to have positive significant elasticities for maize in Northern Ghana. As one can note, fertilizer input and agro-chemicals are likely to stimulate production to a lower extent than land and seed inputs. This indicates that improvement in application of fertilizers and other chemicals is needed to increase sustainability of farming.

Table 4. Partial and scale elasticity at sample mean.

\begin{tabular}{cc}
\hline Variable & Input Elasticity \\
\hline Labor & -0.33 \\
Agro-chemicals & 0.22 \\
Fertilizer & 0.10 \\
Seed & 0.48 \\
Land size & 0.50 \\
Scale elasticity & 0.97 \\
\hline
\end{tabular}

The technology seems to be close to that of constant returns to scale as scale elasticity is slightly below unity at 0.97. Noteworthy, Etwire et al. [11] found soybean farmers in Saboaba Chereponi to be producing at decreasing returns to scale of 0.75 . The present results suggest that a $1 \%$ increase in the use of all inputs will increase the output by $0.97 \%$, ceteris paribus.

The labor elasticity suggests a $1 \%$ increase in labor will decrease output by $0.33 \%$, other inputs remaining constant, and this might be explained by the fact that soybean production in Northern Ghana is facilitated on small scale with average farm size of 0.89 hectare and mean household size of 11 persons. The small land size and large household therefore suggest that labor is being overused. It can also be explained by the lack of machinery employed in soybean production in the area, making farmers dependent on manual labor for all operations on the farm except for plowing. The dependence of Ghanaian agriculture on manual labor is stressed by Asante et al. [33] who also finds labor to have negative returns to output in Ghana. The findings of this study is also substantiated by the those of Asogwa et al. [34] who found that land, fertilizer and seeds have positive elasticities, whereas it is not the case for labor.

\subsection{Technical Efficiency Estimates}

The mean technical efficiency for soybean farms in Northern Ghana is estimated to be 0.885 with a minimum of 0.105 and maximum level of 0.995 . This indicates the average soybean farmers can increase their production of soybean by $11.5 \%$ with the current level of inputs used. Similarly, Kaur et al. [35] reported mean efficiencies of wheat production to be $87 \%, 94 \%, 86 \%$ for semi-hilly, central, south-western parts of Punjab state, respectively (sample mean-87\%). Indeed, the high levels of efficiency could be a result of the numerous capacity building programs farmers receive from NGOs and other development agencies in the area and thereby enhance the utilization of inputs. Anyway, 
the results suggest the least efficient farmer can increase their level of production by $89.5 \%$ without altering the level of input use.

Figure 1 shows the distribution of efficiency scores by means of kernel density plot. Most farmers (71.4\%) operate at efficiency levels above 0.90 while less than $10 \%$ operate at efficiency levels below 0.60 . This means that about $9.2 \%$ of farmers can increase their production of soybean by $40 \%$ or higher extent without increasing the current level and quantities of inputs used. This implies resource waste is not that acute among Northern Ghana soybean farmers.

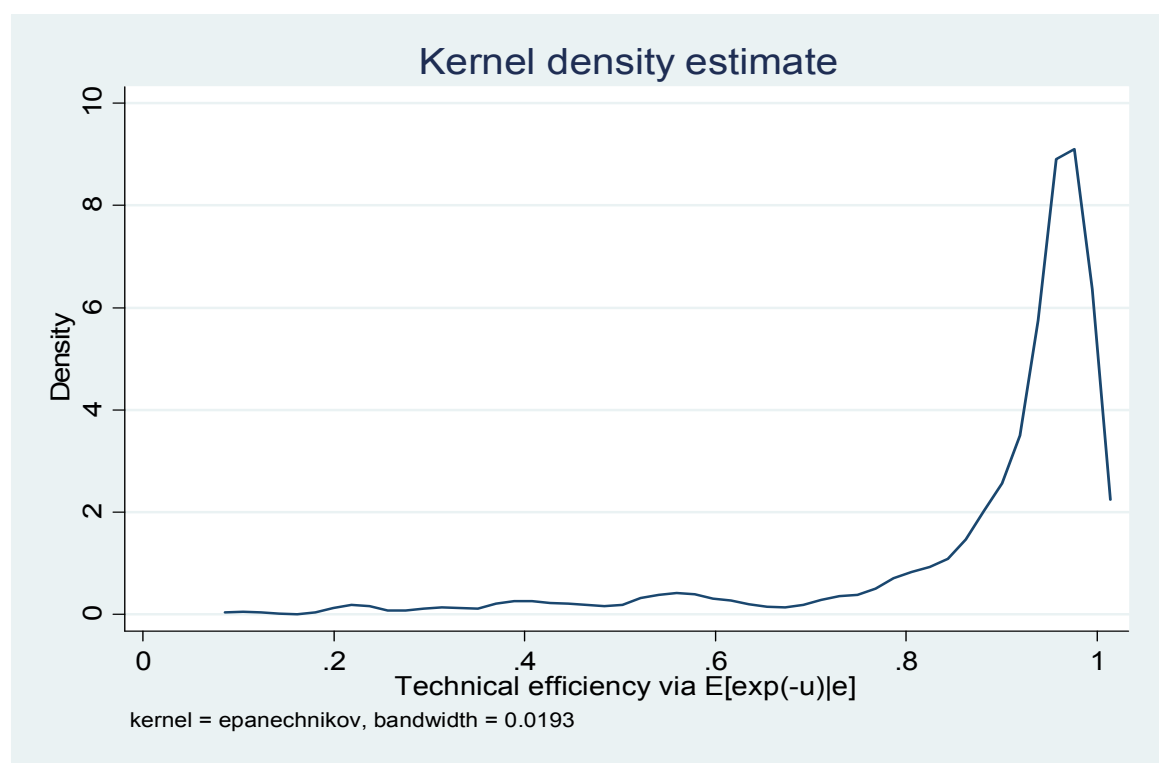

Figure 1. Distribution of the efficiency scores.

However, the high level of technical efficiency can also be explained by the majority of the farmers having a similar mode of production and resource utilization. It could be the reason why farmers have higher efficiency levels but lower outputs, as yields are below achievable levels with an average yield of $0.89 \mathrm{t} /$ ha, i.e., much below the achievable yield of $2 \mathrm{t} /$ ha as stipulated by Akramov and Malek [3]. This could be the outcome of the facilitations from NGOs and development agencies as training and other capacity building programs mostly seek to improve farmers' managerial skills. It is therefore possible that the high efficiency scores accompanied by low outputs could be a result of low input usage. The perception by farmers that soybean is a crop that does not require fertilizer application for its production is evident as only $23 \%$ and $30 \%$ of the farmers apply fertilizer and agro-chemicals, respectively, on their soybean farms. Low input use can lead to low yields or outputs even if the inputs are used efficiently. This viewpoint portrays that NGOs and development agencies have still much to do with regards to levels of inputs required for soybean production improvement. What is more, other factors, such as erratic rains and pests (rodents), are not uncommon in Northern Ghana and can affect outputs of soybean significantly. Table 5 below summarizes the distributions of efficiencies for facilitated and non-facilitated farms.

The data in Table 5 show that the percentage of non-facilitated farmers (14\%) with efficiency less than 0.6 is higher than that for facilitated farms (6\%). In addition, farmers with efficiency above 0.9 are more frequent among facilitated farmers $(74 \%)$ than among non-facilitated farmers $(67 \%)$. Thus, much of the farmers in the low efficiency cohorts are those not facilitated whilst much of the higher efficiency observations come from the facilitated farmers. This supports the argument that NGOs and development agency facilitations lead to effective resource utilization and, hence, higher efficiencies among farmers. 
Table 5. Distribution of observations across efficiency levels and facilitation by NGOs.

\begin{tabular}{cccccc}
\hline \multirow{2}{*}{ Group } & \multicolumn{3}{c}{ Distribution across Groups (\%) } & \multicolumn{2}{c}{ Average } \\
\cline { 2 - 6 } & TE $\leqslant \mathbf{0 . 6 0}$ & $\mathbf{0 . 6 0}<$ TE $\leqslant \mathbf{0 . 9 0}$ & $\mathbf{0 . 9 0}<$ TE & Point Estimate & Confidence Interval \\
\hline Facilitated & 6 & 20 & 74 & 0.902 & $(0.915,0.995)$ \\
Non-facilitated & 14 & 19 & 67 & 0.858 & $(0.920,1.000)$ \\
Total & 9 & 19 & 71 & 0.885 & $(0.918,0.998)$ \\
$p$-value $(t$-test $)$ & & & & 0.0254 & \\
\hline
\end{tabular}

Notes: (i) two-sample $t$-test with unequal variances compares the average technical efficiencies for facilitated and non-facilitated farms; (ii) confidence intervals are based on Horrace et al. [36].

To further substantiate the contribution of NGOs to improving technical efficiency, a two sample $t$-test is carried out to ascertain whether the differences in technical efficiency between farmers who participate in development projects and facilitations by NGOs and farmers who do not participate in development projects and are not facilitated by NGOs working in Northern Ghana are statistically significant. The null hypothesis of equal means for the two groups is rejected at a $5 \%$ level of significance, as indicated in Table 5 . This, therefore, provides strong evidence in regards to a positive influence of NGOs and development agencies on technical efficiency. Farmers who are facilitated by NGOs and development organization operate with the mean efficiency score of 0.902 while those not facilitated operate at 0.858 , which is 0.044 lower compared to those facilitated.

\subsection{Determinants of Technical Efficiency}

Following Equation (6), the negative coefficients in technical inefficiency model are interpreted as those reducing inefficiency. Therefore, technical efficiency increases with the value of such a factor and vice versa. As shown in Table 6 , the conventional factor inputs are included into the inefficiency function as exogenous factors affecting technical efficiency besides the socio-economic factors or characteristics of farmers as suggested by [31]. With the exception of agro-chemicals, all the classical inputs are significant. However, the coefficients near the factors inputs are both positive and negative implying different degrees of input exploitation.

Table 5 already suggested facilitated farms are more efficient if opposed to non-facilitated ones. The corresponding variables in the inefficiency equation (Table 6) capture the pure effect of facilitation. Specifically, the coefficient of development agencies and NGOs facilitation, viz. NGO facilitation, is negative and significant at $5 \%$. This suggests that the services provided by development organizations and NGOs to farmers, e.g., training, information support, credit and other input supply, technology transfer, and market linkages as well as monitoring and evaluations of farmer's production practices, help the farmers to use their productive resources efficiently.

As regards the earlier literature, Seyoum et al. [37] also found farmers, who participated in the SG2000 project on maize production, to be more technically efficient that non-participants in Ethiopia. Though this research cannot ascertain and conclude on the indirect effects of NGOs and development organization facilitation on non-participants, it is assumed that the trickling down effects of the NGOs and other development organizations facilitation are reaching most farmers in the communities even if not facilitated directly, as farmers tend to learn and share knowledge and adopt technologies being practiced by their peers. This may explain the marginal difference between facilitated and non-facilitated farmers, otherwise the margins would have been wider. However, further studies need to be conducted to ascertain the attribution of the difference in technical efficiency to facilitation by NGOs and other development organizations/agencies and projects. 
Table 6. Estimates of efficiency effects model.

\begin{tabular}{ccc}
\hline Variables & Coefficient & $t$-Statistic \\
\hline Ln Labor & $-0.980^{* * *}$ & -3.390 \\
Ln Agro-Chemicals & -0.173 & -0.857 \\
Ln Fertilizer & $0.257^{*}$ & 1.864 \\
Ln Seeds & $2.672^{* * *}$ & 4.037 \\
Ln Land & $-1.023^{*}$ & -1.839 \\
Gender & $0.306^{*}$ & 1.809 \\
Age & $0.023^{* * *}$ & 2.787 \\
Experience & -0.024 & -1.052 \\
Education & $0.035^{* * *}$ & 1.980 \\
Farmer Group & $0.639^{* *}$ & 1.994 \\
Credit & -0.140 & -0.764 \\
Extension & $-0.085^{* *}$ & -2.137 \\
NGO facilitation & $-0.656^{* *}$ & -2.192 \\
Household size & -0.010 & -0.525 \\
Fertilizer use & $-1.250^{* *}$ & -2.247 \\
Improved seeds & $-0.462^{* *}$ & -2.023 \\
Northern Region & $-0.553^{* *}$ & -2.137 \\
intercept & $-6.138^{* * *}$ & -2.661 \\
N & 349.000 & - \\
Log likelihood & -221.584 & - \\
\hline
\end{tabular}

Notes: (i) $p$-values are denoted as follows: ${ }^{*} p<0.1 ;{ }^{* *} p<0.05 ;{ }^{* * *} p<0.01$; (ii) efficiency effects are estimated simultaneously with the production frontier (Table 3 ).

In addition, a prerequisite for most NGO and development agency facilitation is the formation of FBOs due to the benefits that can be derived. However, contrary to our expectations, group membership is found to reduce farmers' technical efficiency. We also attempted to introduce an interaction term to capture the effects of both receiving NGO facilitation and belonging to an FBO. However, the latter variable appeared to be insignificant and thus was not considered for the further analysis. As shown in Table 6, the coefficient of farmer group membership is positive and significant at $5 \%$, which implies that belonging to farmer groups reduces farmer's technical efficiency. A similar result is reported by Addai et al. [38], although the difference between members and non-members was not significant in that case. They explained that the underlying reason could be an inappropriate diversion of resources received from the groups by group members, which is very likely to be the case in this study. This, however, contradicts our expectations that belonging to a farmers' group allows members accessing resources easily and timely as well as learning from their peers and ultimately improving their production as indicated by Alwarritzi et al. [18]. Indeed, [18] found positive relationship between technical efficiency and farmer group membership. The results of this study, indeed, can be explained by the fact that, in some cases, farmers' groups in Northern Ghana are formed solely to enjoy the benefits from the development organizations and NGO projects. This, obviously, precludes functioning towards the core objectives stipulated by the NGOs and development agencies. Furthermore, most farmer groups are engaged in demand pooling to purchase inputs at reduced prices, and, therefore, are less keen on implementing practices that would improve the utilization of the acquired inputs. All in all, members may access inputs but may not use these optimally. The group structure and dynamics as well as the motives for joining groups, if not well defined and adjusted, can also reduce the ability of the groups to deliver on their objective of improving productivity as suggested by Addai et al. [38]. Moreover, the inverse relationship between membership in farmer groups and technical efficiency could also be the result of poor cohesion or weak commitments among members in farmers' groups, which emanate from lack of downward accountability. This makes many FBOs too weak to exploit their benefits and economics of scale [39]. It is therefore suggested that interventions by NGOs and development agencies should include strengthening farmers' capacities to challenge exclusion and demand accountability. Alternatively, non-group members' efficiency may be higher as they operate individually and may not have access to inputs eventually putting more efforts into reducing input waste. 
As regards the other determinants of technical efficiency, the results in Table 6 imply the gender of a farmer is significant at $10 \%$ in determining technical efficiency of soybean production in Northern Ghana with a positive coefficient indicating males are more efficient in soybean production than females. This was expected as agriculture in Ghana and Northern Ghana is dominated by males who are more favored in accessing production resources and information compared to females who are burdened with household and other social obligations like caring for children in the household. Abatania et al. [14], Donkoh et al. [15] and Amoah et al. [40] also found gender to have significant influence on technical efficiency. Other socio-economic characteristics of farmers, such as age and education level, were significant at $1 \%$ and $5 \%$, respectively, with inverse relationships with technical efficiency. These results are in lines with Alwarritzi et al. [18] and Bozoğlu and Ceyhan [41] who found similar results for age. This situation, however, contradicts to that in Europe, where a study by Nowak et al. [42] indicated the existence of positive relationship between age and technical efficiency.

One can argue that the use of improved and certified seeds needs to be treated as a different technology. However, we follow the approach taken in previous studies [13,28,40,43-45], where the use of improved and certified seeds was treated as an explanatory variable, access to which is also being facilitated by NGOs and development agencies. The use of improved and certified seeds and the use of fertilizer were both significant. The associated coefficients indicate a positive contribution of the said factors towards technical efficiency. This was not surprising as Amoah et al. [40] suggested a positive relationship between efficiency and use of improved seeds. This demonstrates access to and utilization of these inputs improves efficiency of soybean production. Therefore, NGOs and development agencies need to strive to increase access to improved seeds and fertilizers as current levels of application are low. Indeed, it is a long-term task to make the high efficiency levels meaningful by raising outputs and consequently helping to alleviate poverty. Extension contact is also a key instrument in pushing technical efficiency up as it positively influences technical efficiency among smallholder farmers.

Furthermore, technical efficiency is also significantly $(p<0.05)$ influenced by the regional location of farmers. Farmers in the Northern region are found to be more efficient in soybean production than those from Upper West and East regions collectively. These results can be attributed to the fact that access and availability of inputs and production services as well as soils and climatic conditions vary across the regions. Northern region, for instance, hosts most of the development organizations (such as the NRGP and the SADA; and such NGOs as the ACDEP, the IFDC, and ADVANCE), farmers have access to plowing services (such as tractors), which are not the case for Upper East and West regions. In addition, variations in social values exist among the regions, especially in Muslim dominated areas like Upper West Sissala districts, where women are not encouraged to farm and this may influence technical efficiency.

Finally, such socio-economic factors as farmers experience in soybean farming, access to credit and household size were not significant in their influence on technical efficiency.

To address the possible issue of endogeneity, which, in our case, might arise due to self-selection bias, we consider some additional contextual variables as proxies to farmers' attitudes towards farming. These might explain farmers' decisions to join projects by NGOs, yet are not likely to affect output levels directly. Specifically, Output sold, Perception on farming, Gender of household head, and Farmer's exposure are related to entrepreneurship abilities and the degree of market integration, which, in turn, could trigger participation in the projects. However, it is due to Table S1 that the differences in the aforementioned variables are not significant across facilitated and non-facilitated farms. As there have been no clear patterns of farmers' characteristics leading to facilitation by NGOs, one can assume that the issue of endogeneity is not acute in the present study. However, endogeneity needs to be seriously considered in further studies on the impacts of NGOs by considering (i) additional variables in the questionnaire survey and (ii) applying improved techniques for estimation.

\section{Conclusions}

The influence of NGOs and development agencies facilitation on productivity improvement is a topical issue that has not been further explored in Africa, specifically in Ghana. NGOs and development agencies are involved in building farmers' capacities, assisting farmers to access inputs, 
markets and information, all geared towards poverty alleviation and increasing farming sustainability. This study, therefore, employed the stochastic frontier approach to estimate the production function and explore the influence of NGOs and development agencies, among other socio-economic factors, on technical efficiency. Cross sectional data from 349 smallholder soybean producers in Northern Ghana for the 2014 production season was used in the analysis.

The results indicate that land, fertilizer, seeds and agro-chemicals have positive elasticities, while labor shows negative elasticity as production is excessively dependent upon manual labor. Low fertilizer and agro-chemicals elasticities imply that improvements in regards to application of these inputs are important in seeking to increase sustainability of soybean farming in Ghana. The mean technical efficiency of 0.885 indicates that production of soybean can be increased by $11.5 \%$ without increasing the level of inputs used. In addition, the high output elasticity with respect to land indicates most of the growth in soybean output in Northern Ghana is to be achieved by increasing the land area cultivated. The findings of this study also indicate that the services of NGOs and development agencies positively influence technical efficiency. On average, farmers facilitated by NGOs and development agencies are $4.4 \%$ more efficient that farmers not facilitated by NGOs. Socio-economic factors that significantly influence technical efficiency include the age, gender, education, membership of farmer group (FBO), extension visits, fertilizer use, improved seed use and regional location of farmer.

Although the efficiency scores are rather high with over $70 \%$ of farmers showing efficiency scores above 0.9 , yields are relatively low $(0.89 \mathrm{t} / \mathrm{ha})$. This, therefore, calls for efforts towards intensification of soybean production in the area through the promotion of improved seeds and fertilizer utilization to offset the declining soil fertilities. NGOs and development agencies also need to consider extending their facilitation for farmers to access improved production services, such as mechanized planting services and threshing. This would enable ensuring timely execution of the key operations, thus increasing output as well as reducing the dependence on manual labor force.

The negative effect of farmer group membership on technical efficiency requires NGOs and development agencies to reconsider farmers' group development, and formulate strategies to strengthen the FBOs in terms of sustainable improvement in soybean production in Northern Ghana. It is also recommended that further studies consider an in-depth analysis to ascertain the attribution of technical efficiency improvements to facilitations by NGOs and development agencies, thus facilitating an impact assessment analysis. Further research should include panel data and larger samples. The robustness could be further improved by applying models accounting for endogeneity related to farmers' decisions on NGO facilitation, as well as taking off-farm revenue into consideration.

Supplementary Materials: The following are available online at www.mdpi.com/2071-1050/8/5/465/s1, Table S1: The differences in partial factor productivity and contextual variables across facilitated and non-facilitated farms.

Acknowledgments: Support by Priority Academic Program Development (PAPD) of Jiangsu Higher Education Institutions, the Jiangsu Center for Food Security Studies, the Collaborative Innovation Center of Modern Grain Circulation and Safety, National Natural Science Foundation of China (71203096 and 71303112), Doctoral Program of Higher Education in China (20120097120042 and 20123204120017), and Fundamental Research Funds for the Central Universities (KYRC201407) is acknowledged. The first author would also like to express his appreciation to the Governments of Ghana and China for their bilateral scholarship through the Chinese Scholarship council (CSC), which made this study possible. All staff of Navrongo-Bolgatanga Catholic Diocese (NABOCADO), especially the Director, David Azupogo, are acknowledged for their support in the field data collection. The corresponding author would like to thank the China Institute for Rural Studies, Tsinghua University, for their support.

Author Contributions: Aniah Dominic Avea and Tianxiang Li proposed the research framework, wrote the protocol and the first draft together with Jing Zhu. Xu Tian and Tomas Baležentis worked on the analysis and interpretation of results and discussion. Michael Rickaille surveyed the literature, carried out proofreading and restructured the paper, while William Funsani worked on the questionnaire design and data collection. All of the research was guided and supervised by Jing Zhu. All of the authors read and approved the final manuscript.

Conflicts of Interest: The authors have declared no conflicts of interest in this paper. 


\section{References}

1. National Development Planning (NDPC). Implementation of Ghana Shared Growth and Development Agenda (GSGDA) 2011-2013, Annual Report 2013; NDPC: Accra, Ghana, 2014.

2. MoFA, Agriculture in Ghana. Facts and Figures (2010); Statistics, Research, and Information Directorate: Accra, Ghana, 2011.

3. Akramov, K.; Malek, M. Analyzing Profitability of Maize, Rice, and Soybean Production in Ghana: Results of PAM and DEA Analysis; Ghana Strategy Support Program (GSSP) Working Paper No. 0028; International Food Policy Research Institute: Washington, DC, USA, 2012.

4. Millennium Development Authority (MiDA). Investment Opportunity Ghana. In Maize, Soya and Rice Production and Processing Production and Processing; MiDA: Accra, Ghana, 2010.

5. Rusike, J.; van den Brand, G.J.; Boahen, S.; Dashiell, K.; Katengwa, S.; Ongoma, J.; Mongane, D.; Kasongo, G.; Jamagani, Z.; Aidoo, R.; et al. Value Chain Analyses of Grain Legumes in N2Africa: Kenya, Rwanda, Eastern DRC, Ghana, Nigeria, Mozambique, Malawi and Zimbabwe. Available online: https://www.n2africa.org/sites/n2africa.org/files/images/N2Africa_Value\%20chain\%20analyses\% 20of\%20grain\%20legumes\%20in\%20N2Africa.pdf (accessed on 6 May 2016).

6. Farrell, M.J. The measurement of productive efficiency. J. R. Stat. Soc. Ser. A (Gen.) 1957, 120, 253-290. [CrossRef]

7. Salifu, A.; Funk, R.L.; Keefe, M.; Kolavalli, S. Farmer Based Organizations in Ghana; International Food Policy Research Institute (IFPRI): Washington, DC, USA, 2012.

8. Fischer, E.; Qaim, M. Linking smallholders to markets: Determinants and impacts of farmer collective action in Kenya. World Dev. 2012, 40, 1255-1268. [CrossRef]

9. Arellano-López, S.; Petras, J.F. Non-Governmental Organizations and Poverty Alleviation in Bolivia. Dev. Chang. 1994, 25, 555-568. [CrossRef]

10. Mohan, G. The disappointments of civil society: The politics of NGO intervention in Northern Ghana. Political Geogr. 2002, 21, 125-154. [CrossRef]

11. Etwire, P.M.; Martey, E.; Dogbe, W. Technical Efficiency of Soybean Farms and Its Determinants in Saboba and Chereponi Districts of Northern Ghana: A Stochastic Frontier Approach. Sustain. Agric. Res. 2013, 2, 106-116. [CrossRef]

12. Martey, E.; Dogbe, W.; Etwire, P.M.; Wiredu, A.N. Impact of Farmer Mentorship Project on Farm Efficiency and Income in Rural Ghana. J. Agric. Sci. 2015, 7, 79-93. [CrossRef]

13. Djokoto, J.G. Technical Efficiency in Agriculture in Ghana-Analyses of Determining Factors. J. Biol. Agric. Healthc. 2012, 2, 1-10.

14. Abatania, L.N.; Hailu, A.; Mugera, A.W. Analysis of farm household technical efficiency in Northern Ghana using bootstrap DEA. In Proceedings of the 56th Annual Conference of the Australian Agricultural and Resource Economics Society, Fremantle, Australia, 7-10 February 2012.

15. Donkoh, S.A.; Ayambila, S.; Abdulai, S. Technical efficiency of rice production at the Tono irrigation scheme in Northern Ghana. Am. J. Exp. Agric. 2013, 3, 25-42. [CrossRef]

16. Yegon, P.K.; Kibet, L.K.; Lagat, J.K. Determinants of technical efficiency in smallholder soybean production in Bomet District, Kenya. J. Dev. Agric. Econ. 2015, 7, 190-194.

17. Otitoju, M.; Adebo, G.; Arene, C. Identification and Stochastic Analysis of Factors Influencing Technical Inefficiency of Nigerian Smallholder Soybean Farmers. Tropicultura 2014, 32, 197-204.

18. Alwarritzi, W.; Nanseki, T.; Chomei, Y. Analysis of the factors influencing the technical efficiency among oil palm smallholder farmers in Indonesia. Procedia Environ. Sci. 2015, 28, 630-638. [CrossRef]

19. Binam, J.N.; Tonye, J.; Nyambi, G.; Akoa, M. Factors affecting the technical efficiency among smallholder farmers in the slash and burn agriculture zone of Cameroon. Food Policy 2004, 29, 531-545. [CrossRef]

20. Abdulai, A.; Eberlin, R. Technical efficiency during economic reform in Nicaragua: Evidence from farm household survey data. Econ. Syst. 2001, 25, 113-125. [CrossRef]

21. Wilson, P.; Hadley, D.; Ramsden, S.; Kaltsas, I. Measuring and explaining technical efficiency in UK potato production. J. Agric. Econ. 1998, 49, 294-305. [CrossRef]

22. Sherlund, S.M.; Barrett, C.B.; Adesina, A.A. Smallholder technical efficiency controlling for environmental production conditions. J. Dev. Econ. 2002, 69, 85-101. [CrossRef]

23. Lohr, L.; Park, T. Local selling decisions and the technical efficiency of organic farms. Sustainability 2010, 2, 189-203. [CrossRef] 
24. Asogwa, B.; Umeh, J.; Okwoche, V. Poverty and Efficiency among the Farming Households in Nigeria: A Guide for Poverty Reduction Policy. Curr. Res. J. Econ. Theory 2012, 4, 6-10.

25. Asante, B.O.; Afari-Sefa, V.; Sarpong, D.B. Determinants of small scale farmers' decision to join farmer based organizations in Ghana. Afr. J. Agric. Res. 2011, 6, 2273-2279.

26. Aigner, D.; Lovell, C.K.; Schmidt, P. Formulation and estimation of stochastic frontier production function models. J. Econom. 1977, 6, 21-37. [CrossRef]

27. Battese, G.E.; Coelli, T.J. A model for technical inefficiency effects in a stochastic frontier production function for panel data. Empir. Econ. 1995, 20, 325-332. [CrossRef]

28. Simar, L.; Wilson, P.W. Statistical Approaches for Non-parametric Frontier Models: A Guided Tour. Int. Stat. Rev. 2015, 83, 77-110. [CrossRef]

29. Battese, G.E.; Corra, G.S. Estimation of a production frontier model: With application to the pastoral zone of Eastern Australia. Aust. J. Agric. Econ. 1977, 21, 169-179. [CrossRef]

30. Battese, G. On the Estimation of Production Functions Involving Explanatory Variables Which Have Zero Values; Working Paper in Econometrics and Applied Statistics No. 86; Department of Econometrics, University of New England: Armidale, Australia, 1996.

31. Xu, T.; Sun, F.-F.; Zhou, Y.-H. Technical efficiency and its determinants in China's hog production. J. Integr. Agric. 2015, 14, 1057-1068.

32. Abdulai, S.; Nkegbe, P.K.; Donkoh, S.A. Technical efficiency of maize production in Northern Ghana. Afr. J. Agric. Res. 2013, 8, 5251-5259.

33. Asante, B.; Osei, M.; Dankyi, A.; Berchie, J.; Mochiah, M.; Lamptey, J.; Haleegoah, J.; Osei, K.; Bolfrey-Arku, G. Producer characteristics and determinants of technical efficiency of tomato based production systems in Ghana. J. Dev. Agric. Econ. 2013, 5, 92-103. [CrossRef]

34. Asogwa, B.; Ihemeje, J.; Ezihe, J. Technical and allocative efficiency analysis of nigerian rural farmers: Implication for poverty reduction. Agric. J. 2011, 6, 243-251. [CrossRef]

35. Kaur, M.; Mahal, A.K.; Sekhon, M.; Kingra, H. Technical Efficiency of Wheat Production in Punjab: A Regional Analysis. Agric. Econ. Res. Rev. 2010, 23, 173-179.

36. Horrace, W.C.; Schmidt, P. Confidence statements for efficiency estimates from stochastic frontier models. J. Product. Anal. 1996, 7, 257-282. [CrossRef]

37. Seyoum, E.; Battese, G.E.; Fleming, E. Technical efficiency and productivity of maize producers in eastern Ethiopia: A study of farmers within and outside the Sasakawa-Global 2000 project. Agric. Econ. 1998, 19, 341-348. [CrossRef]

38. Addai, K.N.; Owusu, V.; Danso-Abbeam, G. Effects of Farmer-Based-Organization on the Technical Efficiency of Maize Farmers Across Various Agro-Ecological Zones of Ghana. J. Econ. Dev. Stud. 2014, 2, 141-161.

39. Mbeche, R.M.; Dorward, P. Privatisation, empowerment and accountability: What are the policy implications for establishing effective farmer organisations? Land Use Policy 2014, 36, 285-295. [CrossRef]

40. Amoah, S.T.; Debrah, I.A.; Abubakari, R. Technical efficiency of vegetable farmers in Peri-Urban Ghana influence and effects of resource inequalities. Am. J. Agric. For. 2014, 2, 79-87.

41. Bozoğlu, M.; Ceyhan, V. Measuring the technical efficiency and exploring the inefficiency determinants of vegetable farms in Samsun province, Turkey. Agric. Syst. 2007, 94, 649-656. [CrossRef]

42. Nowak, A.; Kijek, T.; Domańska, K. Technical efficiency and its determinants in the European Union agriculture. Agric. Econ. (Zemědělská Ekonomika) 2015, 6, 275-283. [CrossRef]

43. Bhatt, M.S.; Bhat, S.A. Technical Efficiency and Farm Size Productivity-Micro Level Evidence From Jammu \& Kashmir. Int. J. Food Agric. Econ. 2014, 2, 27-49.

44. Chiona, S.; Kalinda, T.; Tembo, G. Stochastic Frontier Analysis of the Technical Efficiency of Smallholder Maize Farmers in Central Province, Zambia. J. Agric. Sci. 2014, 6, 108-118. [CrossRef]

45. Chirwa, E.W. Sources of Technical Efficiency among Smallholder Maize Farmers in Southern Malawi; African Economic Research Consortium Nairobi: Nairobi, Kenya, 2007.

(C) 2016 by the authors; licensee MDPI, Basel, Switzerland. This article is an open access article distributed under the terms and conditions of the Creative Commons Attribution (CC-BY) license (http:/ / creativecommons.org/licenses/by/4.0/). 